\title{
Principais ameaças sanitárias endêmicas da cadeia produtiva de suínos no Brasil
}

\author{
Janice Reis Ciacci Zanella ${ }^{(1)}$, Nelson Morés ${ }^{(1)}$ e David Emilio Santos Neves de Barcellos ${ }^{(2)}$
}

\begin{abstract}
(1)Embrapa Suínos e Aves, BR-153, Km 110, Distrito de Tamanduá, Caixa Postal 321, CEP 89700-991 Concórdia, SC, Brasil. E-mail: janice.zanella@embrapa.br, nelson.mores@embrapa.br (2)Universidade Federal do Rio Grande do Sul, Faculdade de Veterinária, Departamento de Medicina Animal, Avenida Bento Gonçalves, no 9.090, Agronomia, CEP 91540-000 Porto Alegre, RS, Brasil. E-mail: davidbarcellos@terra.com.br
\end{abstract}

Resumo - O Brasil se destaca por ser o quarto maior produtor e exportador de carne suína. A ocorrência de determinadas doenças na produção animal é um dos fatores mais importantes para a suinocultura. Os patógenos de suínos podem ser divididos em três grupos: agentes de doenças transmitidas por alimentos de origem animal; agentes de doenças de importância estratégica para o sistema de defesa sanitária; e agentes de doenças responsáveis por prejuízos na produção animal. Algumas enfermidades, como a peste suína clássica e a febre aftosa, impactam duramente o mercado exportador; doenças endêmicas ou enzoóticas deterioram os índices produtivos e aumentam o custo de produção, com perda da competitividade; e doenças transmitidas por alimentos, embora não afetem os índices produtivos, podem causar danos à saúde humana e prejudicar as relações comerciais. O Brasil, por ser um expoente na produção e na exportação de suínos e derivados, deve estar atento a alguns aspectos relacionados à infraestrutura laboratorial, às medidas de biossegurança e aos cuidados necessários para impedir que determinadas doenças, ainda exóticas, infectem o rebanho brasileiro. Este artigo de revisão aborda as principais doenças endêmicas ou enzoóticas que causam prejuízo à produção de carne suína no Brasil.

Termos para indexação: defesa sanitária animal, doenças enzoóticas, sanidade animal, suinocultura, zoonose.

\section{Main endemic health threats in the swine production chain in Brazil}

\begin{abstract}
Brazil stands out as the fourth largest producer and exporter of pork. The occurrence of certain diseases in animal production is one of the most important factors for swine production. Swine pathogens can be divided into three groups: agents of foodborne illnesses of animal origin; agents of strategically important diseases for the health protection system; and agents of diseases responsible for losses in animal production. Some diseases, such as classical swine fever and foot-and-mouth disease, impact heavily the export market; endemic or enzootic diseases deteriorate production rates and increase production costs, reducing competitiveness; and foodborne illnesses, despite not affecting production indexes, can cause damages to human health and harm commercial relations. Brazil, being an exponent in the production and export of pork and derivatives, must be aware of some aspects related to laboratory infrastructure, biosecurity measures, and care necessary to prevent certain, still exotic, diseases from infecting the Brazilian herd. This review addresses the main endemic or enzootic diseases that cause losses in pork production in Brazil.
\end{abstract}

Index terms: animal health defense, enzootic diseases, animal health, swine production, zoonosis.

\section{Introdução}

A boa situação sanitária da suinocultura brasileira é evidenciada pelos índices produtivos alcançados por seus rebanhos tecnificados, que são semelhantes aos de outros países, onde a atividade também é desenvolvida (Galloway et al., 2007; Salgado et al., 2015). Entre as ações de defesa sanitária animal no Brasil, estão a criação de Granjas de Reprodutores Suídeos Certificadas (GRSC) (Borges et al., 2011; Oliveira et al., 2014b; Brasil, 2016), bem como a concentração de esforços na vigilância, na profilaxia, no controle e na erradicação das doenças listadas pela Organização Mundial de Saúde Animal (OIE) (Ben Jebara et al., 2012; World Organisation for Animal Health, 2016). No entanto, infelizmente, ainda são escassos estudos epidemiológicos que envolvam as principais regiões produtoras de suínos e muitas das doenças de ocorrência enzoótica; a maioria dos trabalhos foca apenas em determinadas regiões ou grupo de produtores (Borges et al., 2011). 
As doenças enzoóticas, também denominadas de doenças de rebanho ou doenças endêmicas, ocorrem em grande parte das granjas tecnificadas de produção de suínos, onde há ampla microbiota de patógenos importantes, que se mantêm em equilíbrio dentro dos rebanhos e são controlados pelas defesas imunes dos animais, pelos cuidados adequados com os fatores predisponentes e pelo uso de medicamentos. A estratégia mais comum é permitir as infecções enzoóticas, mas impedir a multiplicação significativa dos agentes, para que a infecção não atinja o estágio de doença (Fablet, 2009). Cabe destacar que também há patógenos nos suínos que não provocam doença clínica, mas que são importantes na segurança dos alimentos, como, por exemplo, algumas sorovares de Salmonella (Bearson et al., 2013).

Mudanças no perfil epidemiológico das doenças dos suínos podem ser observadas na atualidade (Thrusfield, 2013). Anteriormente, as doenças com maior impacto na produção eram as bacterianas, que, por sua vez, resolviam-se com tratamentos antimicrobianos (Sobestiansky et al., 2012). Contudo, recentemente, as principais doenças de suínos relatadas são multifatoriais e virais, geralmente imunossupressoras, e causam elevada morbidade, mortalidade variável e, principalmente, redução no desempenho com aumento no custo de produção (Brum et al., 2013). A essas doenças, somam-se agentes oportunistas, causadores de complexos de doenças dos sistemas respiratório, digestório e urinário (Menin et al., 2008; Brum et al., 2013; Morés et al., 2015). Além disso, também há maior exigência dos consumidores quanto ao bem estar animal e à segurança dos alimentos. Isso reforça a importância da adoção de instalações e medidas de manejo adequadas para prevenir doenças e sua disseminação (Luning et al., 2015).

Este artigo de revisão aborda as principais doenças endêmicas ou enzoóticas que causam prejuízo à produção de carne suína no Brasil.

\section{Doenças da lista da OIE que afetam os suínos e a situação sanitária do rebanho nacional}

O Brasil obteve, recentemente, reconhecimento internacional de zona livre de peste suína clássica (PSC) (World Organisation for Animal Health, 2016). Esse reconhecimento englobou grande parte do território nacional e implica no atendimento de requisitos sanitários a serem cumpridos pelos estados. Já a peste suína africana (PSA) foi registrada no País na década de 1980, mas foi erradicada por abate sanitário, e, desde então, não houve mais relatos da doença (Tokarnia et al., 2004; Lyra, 2006).

Com relação ao vírus da síndrome reprodutiva e respiratória dos suínos (PRRS), vários estudos epidemiológicos foram realizados no Brasil a partir de 1995, principalmente em plantéis de granjas que importaram suínos e das granjas GRSC; porém, não foi possível identificar nem o vírus nem a doença clínica (Ciacci-Zanella et al., 2004). Dessa forma, apesar de os testes sorológicos utilizados serem muito sensíveis, não foi constatada infecção nos rebanhos brasileiros (Ciacci-Zanella et al., 2004). Portanto, até o momento, não há evidências sorológicas ou virológicas da presença dessa doença no País (Ciacci-Zanella et al., 2004; Massa et al., 2014).

Doenças como triquinelose, encefalomielite pelo vírus Nipah, PRRS, diarreia epidêmica dos suínos (PEDV) e gastrenterite transmissível (TGE) ainda não foram diagnosticadas no Brasil (Brentano et al., 2002; Ciacci-Zanella et al., 2004). Para manter o rebanho brasileiro livre dessas enfermidades, é importante reforçar a biosseguridade e a vigilância sanitária, especialmente quanto às importações de animais vivos, seus produtos e subprodutos, material de multiplicação animal (sêmen, embriões e óvulos), e produtos biológicos e patológicos que podem ser possíveis veiculadores dos agentes (Aguilar et al., 2015). Um plano de contingência bem definido pelas autoridades sanitárias também é fundamental para rapidamente identificar, conter e erradicar um patógeno, em caso de entrada (Oliveira et al., 2014b, 2015; Aguilar et al., 2015).

Grande parte do território brasileiro é zona livre de febre aftosa com vacinação, exceto Santa Catarina, considerada zona livre sem vacinação, que é proibida no Estado (Marques et al., 2015; World Organisation for Animal Health, 2016). Em 2014, os estados de Alagoas, do Ceará, do Maranhão, da Paraíba, de Pernambuco, do Piauí, do Rio do Grande do Norte e a região Norte do Pará foram reconhecidos pela OIE como livres de febre aftosa com vacinação e foram incorporados à zona livre já consolidada no País (Garcia et al., 2015).

\section{Doenças de controle oficial nas granjas GRSC}

Todas as granjas de suídeos que comercializam ou distribuem animais para reprodução ou sêmen, 
sejam elas granjas núcleos ou multiplicadoras, são monitoradas semestralmente para PSC, tuberculose, brucelose e doença de Aujeszky; a sarna sarcóptica é monitorada trimestralmente e a leptospirose, caso não haja vacinação. Para poderem vender ou distribuir seus animais, essas granjas devem estar livres das doenças monitoradas (Brasil, 2016).

Em granjas comerciais, as prevalências da tuberculose e da brucelose são muito baixas (Rosa et al., 2012; Oliveira et al., 2014a). A tuberculose, identificada pelo serviço de inspeção de carnes no abate dos suínos, aparece em aproximadamente $0,002 \%$ dos animais abatidos (Morés et al., 2007). Já a linfadenite granulomatosa, causada por micobactérias do complexo avium, aparece em menos de $0,5 \%$ dos suínos abatidos (Morés et al., 2007; Oliveira et al., 2014a). Levantamentos sorológicos realizados no plantel de reprodutores em algumas regiões do Brasil e nas granjas GRSC apontam que a brucelose suína não é um problema sanitário na suinocultura tecnificada, mas pode vir a ser um em criatórios (Rosa et al., 2012).

A doença de Aujeszky tem sido relatada no rebanho brasileiro desde 1912, e, em determinadas regiões, ocorre de forma esporádica (Schaefer et al., 2006; Ciacci-Zanella et al., 2008). No Brasil, a vacina contra essa doença é permitida, porém seu uso é controlado pelo Ministério da Agricultura, Pecuária e Abastecimento (Mapa). Para o controle oficial, somente é liberado o uso de vacinas deletadas para a glicoproteína gE viral (Brasil, 2016). Em Santa Catarina, onde a infecção, até a década de 1990, atingia cerca de $1 \%$ das criações, foi implantado, em 2001, um programa de erradicação da infecção nos rebanhos suínos, também seguido pelos outros estados da região (Ciacci-Zanella et al., 2008). Assim, no Sul do País, não há relatos da doença desde 2004, o que comprova o sucesso do programa, que serviu de modelo para oficialização do Programa de Controle e Erradicação da Doença de Aujeszky em Suídeos no Brasil. Programas de controle e erradicação semelhantes para esta infecção estão sendo implementados em outros estados onde a suinocultura tecnificada é importante (Groff et al., 2005; Oliveira et al., 2014b, 2015).

\section{Doenças importantes na segurança alimentar}

A Salmonella choleraesuis é a principal sorovar capaz de causar doença clínica em suínos, sendo rara nos rebanhos tecnificados do Brasil (Kich et al., 2011). Entretanto, os suínos podem se infectar com uma variedade de sorovar que não cause a doença clínica, mas que pode ser importante fonte de contaminação para os produtos finais. A prevalência destas sorovares nos suínos de abate é elevada, e as mais frequentes são Typhimurium, Panamá, Senftenberg, Derby e Mbandaka (Kich et al., 2011). Como a Salmonella Typhimurium é a segunda mais importante nas infecções alimentares em humanos, deve-se enfatizar a necessidade e a importância de implementar programas de controle que englobem desde as unidades produtoras e o transporte, até o abate e o interior dos abatedouros (Lima et al., 2016).

Já a toxoplasmose, na espécie suína, pode causar falhas reprodutivas como abortos, repetições de estro, natimortalidade e natimorbidade; no entanto, o maior problema continua sendo a segurança dos alimentos. Por serem importantes reservatórios e fontes dessa infecção às populações humanas, os suídeos tem atraído a atenção de epidemiologistas. Isso porque, apesar de os felídeos serem os únicos hospedeiros definitivos de Toxoplasma gondii, os quais eliminam oocistos nas fezes e podem infectar várias outras espécies de animais, o suíno faz o ciclo intermediário da doença, e, consequentemente, também pode infectar o ser humano (Ortega-Pacheco et al., 2011). Neste aspecto, o gato doméstico que convive nas instalações de suínos, em especial nas fábricas de rações, representa um enorme risco. A prevalência da toxoplasmose suína no Brasil pode variar de região para região, de acordo com hábitos socioculturais e fatores geográficos e climáticos. Os diversos estudos epidemiológicos realizados em criatórios de suínos, em diferentes estados, mostraram soroprevalências que variaram de 1,16 a $51,25 \%$ nos suínos examinados (Almeida et al., 2015). Frente a estes resultados, medidas de biosseguridade relevantes para o controle da infecção foram implementadas nos últimos anos, com o avanço dos sistemas integrados de produção de suínos e da escala de produção no Brasil. Entre essas medidas, destaca-se o uso de rações que são fornecidas pelas indústrias, ou produzidas em fábricas industriais, e que são estocadas nas granjas, em silos metálicos, com distribuição automatizada aos animais.

\section{Doenças entéricas}

A colibacilose na creche ou a síndrome da diarreia pós-desmame ocorre principalmente nas primeiras semanas posteriores ao desmame dos leitões, nas formas de diarreia e doença do edema. Nessa fase,

Pesq. agropec. bras., Brasília, v.51, n.5, p.443-453, maio 2016 DOI: $10.1590 / \mathrm{S} 0100-204 X 2016000500004$ 
ocorrem alterações fisiológicas que se somam a uma série de mudanças muito significativas no manejo, na nutrição, no perfil imunitário, e na pressão de infecção e de ambiente. Isso resulta em um aumento de suscetibilidade às diarreias, cujo agente mais frequente, nesta fase, é a Escherichia coli enterotoxigênica (Etec) (Francis, 2002).

Essa é uma das mais importantes enfermidades na suinocultura brasileira, responsável por expressivas perdas econômicas, em razão do emagrecimento, do atraso no crescimento, da piora da conversão alimentar e da redução no ganho de peso dos animais; do aumento no uso de medicamentos e desinfetantes; da necessidade de assistência veterinária; e da maior predisposição dos animais afetados a infecções secundárias, que causam maior variabilidade no peso dos leitões do lote (Silva et al., 2015). Além de ser considerada a principal responsável por diarreia na creche, a colibacilose pode levar a óbito até $25 \%$ dos animais se não forem adotadas medidas adequadas de prevenção e tratamento (Silva et al., 2015).

Apesar dos relatos de perdas por colibacilose em leitões desmamados, em todo o mundo, a morbidade é extremamente variável, em função dos fatores predisponentes existentes ou não nas criações. A colibacilose pode afetar até $80 \%$ dos animais durante um surto, com média de 30-40\% (Brum et al., 2013). Sabe-se que sorotipos específicos de E. coli desempenham papel central na etiologia da diarreia pós-desmame (Macêdo et al., 2007); contudo, a condição é complexa e multifatorial (Morés et al., 2000). Entre os fatores predisponentes citados, os considerados mais comuns são as alterações na fisiologia digestiva decorrentes do início da ingestão da ração pré-inicial. Em especial, o uso de rações de baixa digestibilidade, o fornecimento de rações em comedouros sujos ou a ingestão de rações já fermentadas geram substratos no intestino delgado que são um meio favorável para a multiplicação da Etec (Morés et al., 2000). Outro fator crítico é o excesso de frio e/ou umidade nas instalações. Também há evidências de que o estresse dos animais nessa fase seja capaz de atuar, pelo processo de "quorum sensing", na estimulação da síntese dos fatores de virulência de $E$. coli. Outras condições estressantes são o desconforto nas condições de transporte, o espaço reduzido nas baias, a mistura de animais de várias origens, a alta pressão de infecção pelo uso de sistema de produção contínuo, e as falhas na limpeza relacionadas à desinfecção das instalações e à limpeza diária das baias (Morés et al., 2000).

A colibacilose usualmente começa de 3-5 dias após o desmame e dura entre 2 e 3 dias, mas pode estender-se por mais alguns dias. Ela também tem sido observada no início do crescimento, principalmente em modelos produtivos que misturam leitões de diferentes origens nos terminadores (Francis, 2002). O principal sinal clínico é a diarreia com consistência que varia de pastosa a líquida, o que gera perda progressiva de peso. Os leitões afetados apresentam apatia, perda de apetite, desidratação e mau estado corporal. Como consequência da desidratação, podem ocorrer hemoconcentração, acidose metabólica e depleção de eletrólitos, que podem ser fatais (Moreno et al., 2012). O diagnóstico é realizado pelo isolamento bacteriano, seguido de PCR multiplex para identificação de genes de fímbrias e toxinas. Para um diagnóstico positivo, espera-se encontrar pelo menos genes de uma fímbria e uma toxina (Vidotto et al., 2009).

A medida inicial para o controle da colibacilose deve ser a identificação e a correção dos fatores predisponentes, sobretudo de aspectos ligados à limpeza e à desinfecção, com priorização, também, da manutenção de ambientes secos e aquecidos para os leitões. Também pode-se suprimir o fornecimento da ração aos animais por um dia e oferecer apenas água medicada e/ou reidratante, com arraçoamento gradativo, em pequenas quantidades, várias vezes ao dia (Morés et al., 2000). Além disso, para o tratamento, podem ser utilizados, por via oral e/ou parenteral, antibióticos de amplo espectro de ação e que ajam com eficiência frente a bactérias gram-negativas (Menin et al., 2008). Recentemente, uma vacina viva comercial vem sendo utilizada no Brasil para o controle de colibacilose pós-desmame (Pejsak, 2013).

A enteropatia proliferativa dos suínos (EPS) é causada por Lawsonia intracellulare. Estudos epidemiológicos, em granjas tecnificadas, indicaram alta prevalência da espécie por meio de exames de PCR ou pela detecção de anticorpos específicos (Faccini et al., 2005). No entanto, as estimativas de perdas econômicas, a prevalência e a real importância da EPS são pouco conhecidas no mundo, inclusive no Brasil (Faccini et al., 2005; França \& Guedes, 2008). A doença, na forma hemorrágica, foi diagnosticada no País em um rebanho, em 1983 (Barcellos, 2000), mas sua frequência é desconhecida, embora afete 
determinados rebanhos nas fases de creche e, principalmente, no início do crescimento (Pereira et al., 2013); portanto, a forma hemorrágica da EPS é importante nos programas genéticos. Para evitar a mortalidade em razão da fase aguda, recomendam-se tratamentos preventivos no alojamento dos animais, na granja destino (Pereira et al., 2013). Contudo, a manutenção dos animais, por períodos longos com medicação antimicrobiana em creches e/ou recrias e em terminações, pode limitar a exposição ao agente e a resposta imune, o que predispõe à ocorrência da doença na fase final da terminação (Pereira et al., 2013).

A disenteria suína pode ocasionar 10 a $90 \%$ de redução da conversão alimentar e entre 13 e $62 \%$ de redução no ganho de peso (Zlotowski et al., 2008). No Brasil, a disenteria suína ocorre desde a década de 1970 e afeta muitos rebanhos. Nas décadas de 1980 e 1990, com a utilização, em larga escala, de antimicrobianos com ação sobre o agente etiológico, poucos casos da doença foram observados no setor produtivo. A partir de 2000, com a proibição ou a redução no uso desses antimicrobianos, apenas casos esporádicos da disenteria suína eram diagnosticados em algumas regiões produtoras (Barcellos, 2000). Entretanto, a partir de 2010, houve a reemergência, em vários estados brasileiros, da infecção, que voltou a um estágio de controle adequado devido aos programas de erradicação adotados nas áreas afetadas (Daniel et al., 2012). Nesses surtos recentes, não se detectou nenhuma diferença, por análise molecular, entre as cepas isoladas de Brachyspira hyodysenteriae (sequenciamento do gene $N O X$ ), o que comprova a relação epidemiológica entre elas (Daniel et al., 2012). Atualmente, não há relatos de novos surtos; porém, episódios de reinfecção têm ocorrido esporadicamente, provavelmente em razão da resistência do agente às condições ambientais, da baixa biosseguridade em algumas granjas, da movimentação/mistura de leitões e da presença de vetores, como ratos, nas granjas.

A colite espiroquetal causada por Brachyspira pilosicoli vem sendo diagnosticada na maioria dos países produtores de suínos (Barcellos, 2000; Barcellos et al., 2000). No Brasil, há poucos relatos da ocorrência dessa infecção, embora formas de diarreia compatíveis com as da doença sejam frequentes em leitões nas fases de crescimento-terminação. Em estudo realizado no Rio Grande do Sul, em 2000, em 38 granjas com relatos de diarreia na fase de recria, foram identificadas as espécies $B$. hyodisenteriae, em sete granjas, e B. pilosicoli em 11 granjas (Barcellos et al., 2000).

A meningite por Streptococcus suis foi diagnosticada no Brasil em 1980 e, atualmente, atinge de forma enzoótica a maioria das granjas tecnificadas (Pagnani et al., 2002). Em 2001, foi realizada uma classificação sorológica das amostras de $S$. suis isoladas de casos clínicos de rebanhos brasileiros, e os mais prevalentes foram os sorotipos 2, 1 e 13, mas um número expressivo de amostras isoladas não foi sorotipado com os sorotipos conhecidos (Pagnani et al., 2002). Hoje, são conhecidos 35 sorotipos capsulares, muitos dos quais convivem em equilíbrio nas criações de suínos (Soares \& Paes, 2013). É importante salientar o potencial, apesar de raro, de $S$. suis afetar seres humanos que trabalham tanto na produção quanto no abate de suínos infectados (Barcellos et al., 2008). O controle, atualmente, baseia-se no uso de vacinas autógenas ou não, em pulsos estratégicos com antimicrobianos e no controle dos fatores de risco (Barcellos et al., 2008).

\section{Doenças respiratórias}

As doenças respiratórias dos suínos costumam se apresentar de forma enzoótica e estão difundidas na maioria das criações brasileiras, com elevados prejuízos econômicos (Sobestiansky et al., 2001). Agentes infecciosos como Mycoplasma hyopneumoniae, Actinobacillus pleuropneumoniae, Pasteurella multocida, Haemophilus parasuis, vírus da influenza A e circovirus tipo 2 (PCV2) (Morés et al., 2015), associados a fatores de risco presentes nos rebanhos, podem ocasionar quadros clínicos respiratórios complexos. O termo "complexo das doenças respiratórias dos suínos" é utilizado para se referir a essa interação de vários agentes infecciosos com os fatores de risco (Fonseca Junior et al., 2015).

Em trabalho de prevalência de rinite atrófica e de pneumonia nas fases de crescimento e terminação de suínos, realizado na região Sul do Brasil entre 1995 e 1997, a rinite e a pneumonia foram diagnosticadas em 42,4 e $42,6 \%$ dos animais avaliados, respectivamente (Sobestiansky et al., 2001). Em outro trabalho em dez estados brasileiros (843 granjas e 104.729 suínos abatidos), foram observadas prevalências de 63,6\% de hepatização pulmonar (com percentual médio de $5,5 \%$ ) e 5,7\% de pleurisia (Morés et al., 2013).

A pleuropneumonia suína por Actinobacillus pleuropneumoniae (App) foi diagnosticada no Brasil no início da década de 1980 (Klein et al., 2003). 
É uma doença importante em algumas criações brasileiras, especialmente em grandes terminações que não fazem o vazio sanitário ou em grandes granjas de ciclo completo. Foram detectados anticorpos em 48,27\% das granjas de suínos, localizadas em alguns estados brasileiros, onde foi realizado estudo soroepidemiológico de amostras de soros (Dutra et al., 2000; Kuchiishi et al., 2007). Entretanto, deve-se considerar que, no Brasil, há vacinas comerciais que podem induzir a formação de anticorpos. Atualmente, no País, dos 15 sorotipos de App diagnosticados, a maioria já foi identificada e os mais importantes são: 5, 3, 6 e 10 (Kuchiishi et al., 2007). Tanto a doença de Glässer quanto a pleuropneumonia suína são mais frequentes em rebanhos melhorados, de grande porte e com bom status sanitário.

A doença de Glässer é uma das enfermidades mais frequentes em suínos acometidos pela circovirose (Fonseca Junior et al., 2015). O isolamento de $H$. parasuis, agente da doença de Glässer, tem sido comum nas criações de suínos no Brasil. Os sorotipos observados com maior frequência são: 1, 4, 5 e 12, dos quais, o mais usual é o 4, de média virulência; deve-se destacar, no entanto, que as 15 sorovares conhecidas já foram encontradas no País (Menin et al., 2005). Mais recentemente, tem sido comum a associação desse agente com influenza em leitões na fase de creche (Morés et al., 2015).

Entre as doenças virais, a circovirose foi diagnosticada no Brasil em 1999 (Ciacci-Zanella \& Mores, 2003) e rapidamente se espalhou em todas as áreas de produção intensiva de suínos. Desde então, a infecção se mantém de forma endêmica na suinocultura tecnificada. O agente é o PCV2 e, desde a primeira identificação até o momento, foram descritos cinco genótipos virais diferentes (Franzo et al., 2015); os principais são: PCV2a e PCV2b, que mostram diferenças na virulência e estão distribuídos mundialmente (Ciacci-Zanella et al., 2009). Os efeitos, na forma de mortalidade ou definhamento de animais, foram devastadores, similares aos observados em praticamente todos os países afetados pela doença. $\mathrm{Na}$ fase crítica do problema, adoeciam principalmente leitões no final da fase de creche e no primeiro mês de crescimento. A mortalidade geralmente ficava entre 3 e 10\%, mas podia atingir até 35\% (Segalés et al., 2013). O controle geralmente se restringia a tentativas de diminuição do impacto da doença, pela adoção de medidas de melhoria de manejo, nutrição e redução da pressão de infecção nos planteis afetados, de acordo com os pontos de Madec. A partir de 2008, foram disponibilizadas vacinas comerciais inativadas e baseadas no genótipo PCV2a. Com o seu uso, houve redução significativa da prevalência da circovirose no Brasil (Guedes, 2012). Atualmente, há relatos de casos esporádicos da doença, mesmo em rebanhos vacinados (Salgado et al., 2015). Entre os fatores que parecem predispor a essas falhas vacinais estão: erros na conservação e/ou na aplicação ou na dosagem da vacina, que, também, podem incluir a não aplicação; interferência de outras doenças em curso na fase da vacinação; uso de vacinas fora da idade ideal, principalmente em leitões muito jovens; e possível insuficiência da imunidade vacinal na proteção contra variantes virais, como a PCV2b (Segalés, 2015). A circovirose, por ser uma doença imunossupressora, deixa os suínos mais vulneráveis a outros agentes de doenças respiratórias e entéricas (Morés et al., 2015). Nesse contexto, o controle da circovirose suína tem se baseado na correção de fatores de risco e no uso de vacinas (Segalés, 2015).

Já a influenza A é uma zoonose e importante virose respiratória causada pelo vírus influenza A. É uma doença infecciosa aguda do trato respiratório que cursa com alta morbidade, de até $100 \%$, e baixa mortalidade, de $2 \%$ ou menos (Vincent et al., 2008). No Brasil, o problema clínico se tornou evidente após a entrada, em 2009, do vírus influenza A H1N1 pandêmico (Schaefer et al., 2011). Em geral, a influenza A ocorre como doença de rebanho e é introduzida pela movimentação de animais (Ciacci-Zanella et al., 2015). Além disso, a doença está amplamente disseminada no mundo e apresenta características zoonóticas (Vincent et al., 2014; Ciacci-Zanella et al., 2015).

O suíno é um hospedeiro importante na dinâmica e na epidemiologia da infecção, pois pode se infectar com vários subtipos virais, originários de diferentes espécies, como as humana, aviária e suína (Vincent et al., 2014). Nas células do sistema respiratório do suíno, um fenômeno conhecido como rearranjo genômico pode ocorrer entre diferentes vírus de influenza (Vincent et al., 2008). Deste rearranjo, novos vírus emergentes podem surgir, alguns mais patogênicos, para os quais os animais ou os humanos não têm imunidade. A pandemia de influenza que infectou humanos em 2009 foi a grande preocupação 
da saúde pública nos últimos anos. Assim como o vírus influenza A H1N1 pandêmico de 2009 (H1N1pdm09), outros vírus influenza já foram identificados em rebanhos no Brasil (Schaefer et al., 2011). A análise de isolados de inúmeros surtos de infecção respiratória aguda em suínos de diferentes faixas etárias, por meio do sequenciamento do genoma viral, revelou a circulação de H1N1pdm09, H1N2 e H3N2 (Schaefer et al., 2011; Ciacci-Zanella et al., 2015). Já a análise de soros coletados de suínos provenientes de granjas comerciais, por meio de testes sorológicos, como Elisa ou inibição da hemaglutinação, mostrou prevalência superior a $60 \%$ de soros positivos para influenza $\mathrm{A}$ (Ciacci-Zanella et al., 2015).

Como a influenza suína é considerada endêmica na maioria dos países produtores de suínos, o seu controle não faz parte de programas sanitários dos governos; esse é o caso de outras enfermidades como a PSC, por exemplo. Assim, não há um fundo federal permanente para essas necessidades. Além disso, por ser um vírus zoonótico, causador de perdas na pecuária e por estar em constante evolução, o seu monitoramento e controle devem ser realizados continuamente.

\section{Doença emergente recente que se tornou endêmica}

A infecção pelo Senecavirus $A$, denominada de perdas neonatais epidêmicas transientes (PNET) ou doença vesicular associada à infecção com o Seneca Valley Virus (SVV), é emergente no Brasil (Leme et al., 2015; Vannucci et al., 2015). Esse é um exemplo de doença emergente que se tornou endêmica e que poderá perder a expressão clínica inicial de surtos. Um dos agravantes é a presença de vesículas, semelhantes à aftosa, em suínos ao abate, o que pode causar problemas econômicos, em razão da destinação das carcaças dada pela inspeção (Leme et al., 2015; Vannucci et al., 2015).

$\mathrm{O}$ agente SVV, pertence à família Picornaviridae e é caracterizado por quadro clínico de doença vesicular idiopática, sem diarreia ou mortalidade epidêmica e transiente dos leitões lactentes (Leme et al., 2015). Em países como Estados Unidos, Canadá, Itália e Nova Zelândia, detectou-se o agente em doença vesicular, a qual ocorreu de forma limitada e afetou poucas granjas esporadicamente. Entretanto, a partir de julho de 2015, foram diagnosticados, nos Estados Unidos, novos casos de doença vesicular com detecção de Senecavirus, desta vez com apresentação de quadros clínicos e patológicos indistinguíveis dos descritos no Brasil (Vannucci et al., 2015).

O local e a data precisos do aparecimento da infecção pelo Senecavirus no Brasil ainda são indeterminados (Leme et al., 2015; Vannucci et al., 2015). Inicialmente, observou-se alta mortalidade de leitões com 1 a 4 dias de idade, com alta frequência de diarreia entre os animais afetados (40 a $60 \%$ ). O quadro clínico era transiente, e o curso nas granjas foi de 5 a 10 dias. No geral, não houve recidivas nos rebanhos afetados; o diagnóstico para as principais doenças que cursavam com alta mortalidade e/ou diarreia em leitões, no período neonatal, foi negativo; e não foram detectadas lesões histopatológicas significativas (Leme et al., 2015; Vannucci et al., 2015). No final de 2014, também começaram a ser relatadas lesões vesiculares, principalmente no focinho e na coroa dos cascos, similares às presentes nas doenças vesiculares dos suínos. A partir daí, houve notificação do problema aos órgãos de defesa sanitária competentes, que passaram a realizar testes diagnósticos diferenciais de doenças vesiculares nos suínos, como febre aftosa, estomatite vesicular, doença vesicular dos suínos e exantema vesicular; todos os testes foram negativos (Leme et al., 2015; Vannucci et al., 2015).

Testes laboratoriais, com sequenciamento de nova geração e PCR, permitiram a identificação do Senecavirus $A$ no líquido vesicular e em diversas vísceras dos animais afetados. Apesar destes resultados, uma associação definitiva do agente com o quadro clínico ainda precisa ser definida, devido à falha nas tentativas de reprodução experimental das lesões com a inoculação do Senecavirus. Há muitas dúvidas sobre a forma de difusão do quadro clínico dessa doença no Brasil. Desconhece-se, por exemplo, a sua forma de entrada no País e o eventual papel de seres humanos, moscas, roedores, animais de reposição e sêmen na disseminação viral para diferentes granjas e estados. O papel de outros possíveis vetores, como caminhões de transporte, grupos de vacinadores, ingredientes de ração ou produtos biológicos, também permanece indeterminado.

\section{Considerações finais}

Grande parte do território brasileiro, onde a suinocultura é tecnificada, é considerada zona livre de febre aftosa com vacinação - exceto Santa Catarina que 
comporta o maior rebanho e é livre sem vacinação - e livre de peste suína clássica sem vacinação. Além disso, doenças de grande impacto econômico na produção de suínos, como a síndrome reprodutiva e respiratória e a diarreia epidêmica, nunca foram diagnosticadas no Brasil. No entanto, doenças da produção, como as demais respiratórias e entéricas citadas neste trabalho, ocorrem no País, embora o seu impacto econômico seja muito variável entre os rebanhos e as regiões.

Para seu controle mais efetivo, é necessário evoluir na infraestrutura de diagnóstico, na vigilância epidemiológica das enfermidades, na logística de movimentação de leitões no setor produtivo, na correção de fatores de risco que favorecem a manifestação de doenças da produção e nas medidas de biosseguridade dos rebanhos. O Brasil deve estar preparado para evitar e para lidar com doenças exóticas que se tornaram endêmicas, como foi o caso, a partir de 2000, da circovirose e, recentemente, das perdas neonatais epidêmicas transientes.

Apesar disso, pode-se considerar que a saúde do rebanho suíno nacional é muito boa e que as medidas de controle utilizadas garantem elevada produtividade, comprovada pelos índices produtivos semelhantes aos de países com tradição na suinocultura. Mesmo assim, ainda devem ser priorizados um sistema de diagnóstico rápido e eficiente, bem como o apoio à defesa sanitária.

\section{Agradecimento}

Ao Conselho Nacional de Desenvolvimento Científico e Tecnológico (CNPq, processo 310387/ 2012-4), pela concessão de bolsa.

\section{Referências}

AGUILAR, C.E.G.; BARALDI, T.G.; SANTOS, A.C.R. dos; NASCIMENTO, K.A.; OLIVEIRA, M.E.F.; OLIVEIRA, L.G. de. Implementação e avaliação das práticas de biosseguridade na produção de suínos. Uma revisão. Revista Brasileira de Higiene e Sanidade Animal, v.9, p.320-333, 2015.

ALMEIDA, W.M. de; MIRANDA, Z.B.; FLAUSINO, W.; COELHO, C.D.; FONSECA, A.B.M.; LOPES, C.W.G. Suínos sororreagentes a Toxoplasma gondii (Apicomplexa: Toxoplasmatinae) enviados para abate e destinados ao consumo humano. Revista Brasileira de Medicina Veterinária, v.37, p.397-400, 2015.

BARCELLOS, D.E.S.N. Colite espiroquetal em suínos: uma doença emergente. A Hora Veterinária, v.20, p.64-69, 2000.
BARCELLOS, D.E.S.N.; UZEDA, M. de; MATHIESEN, M.R.; DUHAMEL, G.E.; KADER, I.I.T.A. Prevalence of Brachyspira species isolated from diarrhoeic pigs in Brazil. Veterinary Record, v.146, p.398-403, 2000. DOI: 10.1136/vr.146.14.398.

BARCELLOS, D.E.S.N. de; MORES, T.J.; SANTI, M.; GHELLER, N.B. Avanços em programas de biosseguridade para a suinocultura. Acta Scientiae Veterinariae, v.36, p.s33-s46, 2008.

BEARSON, S.M.D.; ALLEN, H.K.; BEARSON, B.L.; LOOFT, T.; BRUNELLE, B.W.; KICH, J.D.; TUGGLE, C.K.; BAYLES, D.O.; ALT, D.; LEVINE, U.Y.; STANTON, T.B. Profiling the gastrointestinal microbiota in response to Salmonella: low versus high Salmonella shedding in the porcine host. Infection, Genetics and Evolution, v.16, p.330-340, 2013. DOI: 10.1016/j. meegid.2013.03.022.

BEN JEBARA, K.; CÁCERES, P.; BERLINGIERI, F.; WEBER-VINTZEL, L. Ten years' work on the World Organisation for Animal Health (OIE) Worldwide Animal Disease Notification System. Preventive Veterinary Medicine, v.107, p.149-159, 2012. DOI: 10.1016/j.prevetmed.2012.08.008.

BORGES, S.R.T.; SOUZA, L.C. de; SILVA, R.C. da; ALMEIDA, E. de. Avaliação dos níveis de biosseguridade das granjas de reprodutores suínos certificadas do estado de São Paulo, Brasil. Veterinária e Zootecnia, v.18, p.417-431, 2011.

BRASIL. Ministério da Agricultura Pecuária e Abastecimento. Animal. 2016. Disponível em: <http://www.agricultura.gov.br/ portal/page/portal/Internet-MAPA/pagina-inicial/animal $>$. Acesso em: 18 fev. 2016.

BRENTANO, L.; CIACCI-ZANELLA, J.R.C.; MORES, N.; PIFFER, I.A. Levantamento soroepidemiológico para coronavírus respiratório e da gastroenterite transmissível e dos vírus de influenza H3N2 e H1N1 em rebanhos suínos no Brasil. Concórdia: Embrapa Suínos e Aves, 2002. 6p. (Embrapa Suínos e Aves. Comunicado técnico, 306).

BRUM, J.S.; KONRADT, G.; BAZZI, T.; FIGHERA, R.A.; KOMMERS, G.D.; IRIGOYEN, L.F.; BARROS, C.S.L. Características e frequência das doenças de suínos na Região Central do Rio Grande do Sul. Pesquisa Veterinária Brasileira, v.33, p.1208-1214, 2013. DOI: 10.1590/S0100-736X2013001000006.

CIACCI-ZANELLA, J.R.; AMARAL, A.L. do; VENTURA, L. das V.; MORÉS, N.; BORTOLUZZI, H. Erradicação da doençã de Aujeszky em Santa Catarina: importância da condição sanitária das leitoas de reposição. Ciência Rural, v.38, p.749-754, 2008. DOI: 10.1590/S0103-84782008000300024.

CIACCI-ZANELLA, J.R.; MORÉS, N. Diagnosis of post-weaning multisystemic wasting syndrome in pigs in Brazil caused by porcine circovirus type 2. Arquivo Brasileiro de Medicina Veterinária e Zootecnia, v.55, p.522-527, 2003. DOI: 10.1590/ S0102-09352003000500002.

CIACCI-ZANELLA， J.R.; SIMON， L.S.; PINTO, L.S.; VIANCELLI, A.; FERNANDES, L.T.; HAYASHI, M.; DELLAGOSTIN, O.A.; ESTEVES, P.A. Detection of porcine Circovirus type 2 (PCV2) variants PCV2-1 and PCV2-2 in Brazilian pig population. Research in Veterinary Science, v.87, p.157-60, 2009. DOI: 10.1016/j.rvsc.2008.12.001. 
CIACCI-ZANELLA， J.R.; TROMBETTA， C.; VARGAS， I.; COSTA, D.E.M. da. Lack of evidence of porcine reproductive and respiratory syndrome virus (PRRSV) infection in domestic swine in Brazil. Ciência Rural, v.34, p.449-455, 2004. DOI: 10.1590/ S0103-84782004000200018.

CIACCI-ZANELLA, J.R.; SCHAEFER, R.; GAVA, D.; HAACH, V.; CANTÃO, M.E.; COLDEBELLA, A. Influenza A virus infection in Brazilian swine herds following the introduction of pandemic 2009 H1N1. Veterinary Microbiology, v.180, p.118-122, 2015. DOI: $10.1016 /$ j.vetmic.2015.08.021.

DANIEL, A.G. de S.; GABARDO, M. de P.; NEVES, S.M.N.; GUEDES, R.M.C. Caracterização das espécies de Brachyspira sp. e aspectos referentes à sensibilidade antimicrobiana. Agrotec: Revista Técnico-Científica Agrícola, v.4, p.28-33, 2012.

DUTRA, V.; PIFFER, I.; VARGAS, A.C. de; GUIDONI, A.; KLEIN, C. Padronização do teste ELISA baseado em antígeno capsular purificado dos sorotipos 3, 5 e 7 de Actinobacillus pleuropneumoniae. Ciência Rural, v.30, p.281-286, 2000. DOI: $10.1590 / \mathrm{S} 0103-84782000000200014$.

FABLET, C. An overview of the impact of the environment on enzootic respiratory diseases in pigs. In: ALAND, A.; MADEC, F. Sustainable animal production: the challenges and potential developments for professional farming. The Netherlands: Wageningen Academic Publishers, 2009. p.239-260.

FACCINI, G.S.; GUEDES, R.M.C.; PESCADOR, C.A.; CRUZ, C.E.F.; DRIEMEIER, D. Diagnóstico histoquímico e imunoistoquímico da enteropatia proliferativa (Lawsonia intracellularis) em suínos. Arquivo Brasileiro de Medicina Veterinária e Zootecnia, v.57, p.569-575, 2005. DOI: 10.1590/ S0102-09352005000500001.

FONSECA JUNIOR, A.A.; NONAKA, C.K.V.; GUEDES, E. de O.; LOBATO, Z.I.P.; DIAS, A.S.; NASCIMENTO, J.A.F.B. do; KLEIN, C.S.; REIS, J.K.P. dos; HEINEMANN, M.B. Detecção de agentes associados com doenças respiratórias de suínos por PCR em tempo real. Revista Brasileira de Saúde e Produção Animal, v.16, p.300-307, 2015. DOI: 10.1590/S1519-99402015000200005.

FRANÇA, S. de A.; GUEDES, R.M.C. Antimicrobianos para o controle da enteropatia proliferativa suína. Ciencia rural, v.38, p.288-296, 2008. DOI: 10.1590/S0103-84782008000100050.

FRANCIS, D.H. Enterotoxigenic Escherichia coli infection in pigs and its diagnosis. Journal of Swine Health and Production, v.10, p.171-175, 2002.

FRANZO, G.; CORTEY, M.; OLVERA, A.; NOVOSEL, D.; DE CASTRO, A.M.M.G.; BIAGINI, P.; SEGALÉS, J.; DRIGO, M. Revisiting the taxonomical classification of Porcine Circovirus type 2 (PCV2): still a real challenge. Virology Journal, v. 12, 2015. DOI: 10.1186/s12985-015-0361-X.

GALLOWAY, J.N.; BURKE, M.; BRADFOR, G.E.; NAYLOR, R.; FALCON, W.; CHAPAGAIN, A.K.; GASKELL, J.C.; MCCULLOUGH, E.; MOONEY, H.A.; OLESON, K.L.; STEINFELD, H.; WASSENAAR, T.; SMIL, V. International trade in meat: the tip of the pork chop. Ambio: A Journal of the Human Environment, v.36, p.622-629, 2007.

GARCIA, D.C.C.; SÁ, C.V.G.C. de; McMANUS, C.M.; MELO, C.B. de. Impactos do surto de febre aftosa de 2005 sobre as exportaçãoes de carne bovina brasileira. Ciência Animal Brasileira, v.16, p.525-537, 2015. DOI: 10.1590/1089-6891v16i426158.

GROFF, F.H.S.; MERLO, M.A.; STOLL, P.A.; STEPAN, A.L.; WEIBLEN, R.; FLORES, E.F. Epidemiologia e controle dos focos da doença de Aujeszky no Rio Grande do Sul, em 2003. Pesquisa Veterinária Brasileira, v.25, p.25-30, 2005. DOI: 10.1590/ S0100-736X2005000100006.

GUEDES, R.M.C. Como monitorar infecções subclínicas causando perdas de desempenho na recria e terminação. Sociedad de Medicina Veterinaria del Uruguay, v.48, p.49-51, 2012. Suplemento.

KICH, J.D.; COLDEBELLA, A.; MORÉS, N.; NOGUEIRA, M.G.; CARDOSO, M.; FRATAMICO, P.M.; CALL, J.E.; FEDORKA-CRAY,P.; LUCHANSKY, J.B. Prevalence, distribution, and molecular characterization of Salmonella recovered from swine finishing herds and a slaughter facility in Santa Catarina, Brazil. International Journal of Food Microbiology, v.151, p.307-313, 2011. DOI: 10.1016/j.ijfoodmicro.2011.09.024.

KLEIN, C.S.; PIFFER, I.A.; SILVA, S.C. da; SCHRANK, A.; FÁVERO, M.B.; SCHRANK, I.S. Detection of Actinobacillus pleuropneumoniae by PCR on field strains from healthy and diseased pigs. Current Microbiology, v 46, p.443-447, 2003.

KUCHIISHI, S.S.; KICH, J.D.; RAMENZONI, M.L.F.; SPRICIGO, D.; KLEIN, C.S.; FÁVERO, M.B.B; PIFFER, I.A. Sorotipos de Actinobacillus pleuropneumoniae isolados no Brasil de 1993 a 2006. Acta Scientiae Veterinariae, v.35, p.79-82, 2007.

LEME, R.; ZOTTI, E.; ALCÂNTARA, B.K.; OLIVEIRA, M.V.; FREITAS, L.A.; ALFIERI, A.F.; ALFIERI, A.A. Senecavirus $A$ : an emerging vesicular infection in Brazilian pig herds. Transboundary and Emerging Diseases, v.62, p.603-611, 2015. DOI: $10.1111 /$ tbed.12430.

LIMA, A.L.; RODRIGUES, D.P.; ARAÚJO, M.S.; REIS, E.M.F.; FESTIVO, M.L.; RODRIGUES, E.C.P.; LÁZARO, N.S. Sorovares e perfil de suscetibilidade a antimicrobianos em Salmonella spp. isoladas de produtos de origem suína. Arquivo Brasileiro de Medicina Veterinária e Zootecnia, v.68, p.39-47, 2016. DOI: 10.1590/1678-4162-7997.

LUNING, P.; KIREZIEVA, K.; HAGELAAR, G.; ROVIRA, J.; UYTTENDAELE, M.; JACXSENS, L. Performance assessment of food safety management systems in animal-based food companies in view of their context characteristics: a European study. Food Control, v.49, p.11-22, 2015. DOI: 10.1016/j. foodcont.2013.09.009.

LYRA, T.M.P. La erradicación de la peste porcina africana en el Brasil, 1978-1984. Revue Scientifique et Technique/ Office International des Épizooties, v.25, p.93-103, 2006.

MACÊDO, N.R.; MENEZES, C.P.L.; LAGE, A.P.; RISTOW, L.E.; REIS, A.; GUEDES, R.M.C. Detection of pathogenic strains by multiplex PCR and antimicrobial sensitivity of Escherichia coli isolated from piglets. Arquivo Brasileiro de Medicina Veterinária e Zootecnia, v.59, p.1117-1123, 2007. DOI: 10.1590/ S0102-09352007000500005.

MARQUES, G.H.F.; DE STEFANO, E.; RIBEIRO, C.P.; TURISSI, L.H.A.; DIAS, R.A.; NARANJO, J.; POZZETTI, P.S. ; COSTA, J.F.; PITUCO, E.M. A experiência brasileira na 
erradicação da febre aftosa e o emprego do sistema I-ELISA $3 \mathrm{ABC} / \mathrm{EITB}$ para certificação sanitária de bovinos e bubalinos. Arquivos do Instituto Biológico, v.82, p.1-11, 2015. DOI: 10.1590/1808-1657000282013

MASSA, R.; PICINATO, M.A. de C.; SANTANA, C.H.; ALMEIDA, H.M. de S.; GATTO, I.R.H.; OLIVEIRA, L.G. de. Situação atual da disseminação do vírus da síndrome reprodutiva respiratória em suínos (PRRSV) no mundo e os perigos de introdução no Brasil. Revista Brasileira de Higiene e Sanidade Animal, v.8, p.112-131, 2014.

MENIN, Á.; GAVA, D.; VAZ, E.K. Aspectos gerais sobre a infecção por Haemophilus parasuis em suínos - revisão. Revista de Ciências Agroveterinárias, v.4, p.148-156, 2005.

MENIN, Á.; RECK, C.; SOUZA, D. de; KLEIN, C.; VAZ, E. Agentes bacterianos enteropatogênicos em suínos de diferentes faixas etárias e perfil de resistência a antimicrobianos de cepas de Escherichia coli e Salmonella spp. Ciência Rural, v.38, p.1687-1693, 2008. DOI: 10.1590/S0103-84782008000600030.

MORENO, A.M.; SOBESTIANSKY, J.; BARCELLOS, D. Deficiências nutricionais. In: SOBESTIANSKY, J.; BARCELLOS, D.E.N. de (Ed.). Doenças dos suínos. 2.ed. Goiânia: Cânone, 2012. p.612-626.

MORÉS, M.A.Z.; OLIVEIRA FILHO, J.X.; REBELATTO, R.; KLEIN, C.S.; BARCELLOS, D.E.N.; COLDEBELLA, A.; MORÉS, N. Aspectos patológicos e microbiológicos das doenças respiratórias em suínos de terminação no Brasil. Pesquisa Veterinária Brasileira, v.35, p.725-733, 2015. DOI: 10.1590/ S0100-736X2015000800004

MORÉS, N.; AMARAL, A.L. do; LIMA, G.J.M.M. de; DALLA COSTA, O.A.; COLDEBELLA, A.; MIELE, M.; SANDI, A.J.; OLIVEIRA, P.A.V. de. Produção de suínos em família, sem uso preventivo de antimicrobiano e privilegiando o bem-estar animal. Concórdia: Embrapa Suínos e Aves, 2013. 114p. (Embrapa Suínos e Aves. Sistemas de produção, 5).

MORÉS, N.; SOBESTANSKY, J.; BARIONI JUNIOR, W.; MADEC, F.; DALLA COSTA, O.A.; PAIVA, D.P.; LIMA, G.M.M. de; AMARAL, A.L. do; PERDOMO, C.C.; COIMBRA, J.B.S. Fatores de risco associados aos problemas dos leitões na fase de creche em rebanhos da região Sul do Brasil. Arquivo Brasileiro de Medicina Veterinária e Zootecnia, v.52, p.191-199, 2000.

MORÉS, N.; VENTURA, L.; DUTRA, V.; SILVA, V.S.; BARIONI JR, W.; OLIVEIRA, S.R.; KRAMER, B.; FERREIRA NETO, J.S. Linfadenite granulomatosa em suínos: linfonodos afetados e diagnóstico patológico da infecção causada por agentes do Complexo Mycobacterium avium. Pesquisa Veterinária Brasileira, v.27, p.13-17, 2007. DOI: 10.1590/S0100-736X2007000100003.

OLIVEIRA, F.C.S.; PINHEIRO, S.R.; AZEVEDO, S.S.; SANTOS, C.S.A.B.; LILENBAUM, W.; SOTO, F.R.M.; ROXO, E.; VASCONCELLOS, S.A. Padronização do teste imunoalérgico aplicado ao diagnóstico da tuberculose e micobacterioses em suínos (Sus scrofa) experimentalmente sensibilizados com suspensões oleosas de Mycobacterium bovis ou M. avium inativados. Pesquisa Veterinária Brasileira, v.34, p.123-128, 2014a. DOI: 10.1590/ S0100-736X2014000200005.
OLIVEIRA, L.G. de; OLIVEIRA, M.E.F.; ALEXANDRINO, B.; GATTO, I.R.H.; ALMEIDA, H.M. de S.; SAMARA, S.I. Descrição das ações de vigilância em focos da doença de Aujeszky. Ciência Animal Brasileira, v.16, p.437-447, 2015. DOI: 10.1590/1089-6891v16i328122.

OLIVEIRA, L.G. de; OLIVEIRA, M.E.F.; ALMEIDA, H.M. de S.; GATTO, I.R.H.; SAMARA, S.I. Os desafios da doença de Aujeszky em suínos para a defesa sanitária animal. Veterinária e Zootecnia, v.21, p.370-381, 2014b.

ORTEGA-PACHECO, A.; ACOSTA-VIANA, K.Y; GUZMAN-MARIN, $\quad$ E.; UITZIL-ÁLVAREZ, B.; RODRÍGUEZ-BUENFIL, J.C.; JIMENEZ-COELLO, M. Infection dynamic of Toxoplasma gondii in two fattening pig farms exposed to high and low cat density in an endemic region. Veterinary Parasitology, v.175, p.367-371, 2011. DOI: 10.1016/j. vetpar.2010.10.018

PAGNANI, K.J.R.; CASTRO, A.F.P; GOTTSCHALK, M.; SILVEIRA, W.D.; NAKAZATO, G. Sorotipagem de amostras de Streptococcus suis isoladas de suínos em granjas dos Estados de São Paulo, Minas Gerais e Paraná. Pesquisa Veterinária Brasileira, v.22, p.1-5, 2002. DOI: 10.1590/S0100-736X2002000100002.

PEJSAK, Z. Vaccines against porcine colibacillosis, particularly after weaning. Medycyna Weterynaryjna, v.70, p.3-6, 2013.

PEREIRA, C.E.R.; VANNUCCI, F.A.; SILVA, J.C.P. da; GUEDES, R.M.C. Patogênese da enteropatia proliferativa suína - revisão de literatura. Veterinária e Zootecnia, v.20, p.93-99, 2013.

ROSA, D.C.; GARCIA, K.C.O.D.; MEGID, J. Soropositividade para brucelose em suínos em abatedouros. Pesquisa Veterinária Brasileira, v.32, p.623-626, 2012. DOI: 10.1590/ S0100-736X2012000700006.

SALGADO, R.L.; PEREIRA, P.M.; GONZAGA, N.F.; SOUZA, L.F.L. de; POLÊTO, M.D.; ONOFRE, T.S.; ELLER, M.R.; PEREIRA, C.E.R.; FIETTO, J.L.R.; BRESSAN, G.C.; GUEDES, R.M.C.; ALMEIDA, M.R.; SILVA JÚNIOR, A. A porcine circovirus-2 mutant isolated in Brazil contains low-frequency substitutions in regions of immunoprotective epitopes in the capsid protein. Archives of Virology, v.160, p.2741-2748, 2015. DOI: 10.1007/s00705-015-2567-z.

SCHAEFER, R.; ZANELLA, J.R.C.; BRENTANO, L.; VINCENT, A.L.; RITTERBUSCH, G.A.; SILVEIRA, S.; CARON, L.; MORES, N. Isolation and characterization of a pandemic H1N1 influenza virus in pigs in Brazil. Pesquisa Veterinária Brasileira, v.31, p.761-767, 2011. DOI: 10.1590/S0100-736X2011000900007.

SCHAEFER, R.; ZANELLA, J.R.C.; MORÉS, N.; PAN, K.A.; DAMBROS, R.M.F.; FRACASSO, M.; SCHIOCHET, M.F.; COLDEBELLA, M. Caracterization of Aujeszky's disease virus isolated from South Brazil in the last twenty years by restriction enzyme analysis. Brazilian Journal of Microbiology, v.37, p.390-394, 2006. DOI: 10.1590/S1517-83822006000300035.

SEGALÉS, J. Best practice and future challenges for vaccination against porcine circovirus type 2. Expert Review of Vaccines, v.14, p.473-487, 2015. DOI: 10.1586/14760584.2015.983084.

SEGALÉS, J.; KEKARAINEN, T.; CORTEY, M. The natural history of porcine circovirus type 2: from an inoffensive virus to a devastating swine disease? Veterinary Microbiology, v.165, p.13-20, 2013. DOI: 10.1016/j.vetmic.2012.12.033. 
SILVA, C.V.O.; OLIVEIRA, A.M.A. de; BEZERRA, P.P.N.; EVANGELISTA, J.N.B. Escherichia coli na suinocultura. Aspectos clínicos. Uma Revisão. Revista Brasileira de Higiene e Sanidade Animal, v.9, p.288-293, 2015. DOI: 10.5935/1981-2965.20150028.

SOARES, T.C.S.; PAES, A.C. Prevalência de Streptococcus suis sorotipo 2: discussão da literatura brasileira. Arquivos do Instituto Biológico, v.80, p.367-373, 2013. DOI: 10.1590/ S1808-16572013000300017.

SOBESTIANSKY, J.; DALLA COSTA, O.A.; MORES, N.; BARIONI JUNIOR, W.; PIFFER, I.A.; GUZZO, R. Estudos ecopatológicos das doenças respiratórias dos suínos: prevalência e impacto econômico em sistemas de produção dos estados de Santa Catarina, Rio Grande do Sul e Paraná. Concórdia: Embrapa Suínos e Aves, 2001. 5p. (Embrapa Suínos e Aves. Comunicado técnico, 287).

SOBESTIANSKY, J.; MORÉS, N.; WEIBLEN, R.; REIS, R.; BARCELLOS, D. Classificação das doenças. In: SOBESTIANKSY, J.; BARCELLOS, D.E.N. de (Ed.). Doenças dos suínos. 2.ed. Goiânia: Cânone, 2012. p.14-20.

THRUSFIELD, M. Veterinary epidemiology. $3^{\text {rd }}$ ed. New York: J. Wiley, 2013. 624p.

TOKARNIA, C.H. ; PEIXOTO, P.V.; DÖBEREINER, J.; BARROS, S.S. de; RIET-CORREA, F. O surto de peste suína africana ocorrido em 1978 no município de Paracambi, Rio de Janeiro. Pesquisa Veterinária Brasileira, v.24, p.223-238, 2004. DOI: $10.1590 / \mathrm{S} 0100-736 X 2004000400010$.

VANNUCCI, F.A.; LINHARES, D.C.L.; BARCELLOS, D.E.S.N.; LAM, H.C.; COLLINS, J.; MARTHALER, D. Identification and complete genome of Seneca Valley virus in vesicular fluid and sera of pigs affected with idiopathic vesicular disease, Brazil. Transboundary and Emerging Diseases, v.62, p.589-593, 2015. DOI: $10.1111 /$ tbed.12410.

VIDOTTO, M.C.; LIMA, N.C.S. de; FRITZEN, J.T.T.; FREITAS, J.C. de; VENÂNCIO, E.J.; ONO, M.A. Frequency of virulence genes in Escherichia coli strains isolated from piglets with diarrhea in the North Parana State, Brazil. Brazilian Journal of Microbiology, v.40, p.199-204, 2009. DOI: 10.1590/S1517-83822009000100035.

VINCENT, A.; AWADA, L.; BROWN, I.; CHEN, H.; CLAES, F.; DAUPHIN, G.; DONIS, R.; CULHANE, M.; HAMILTON, K.; LEWIS, N.; MUMFORD, E.; NGUYEN, T.; PARCHARIYANON, S.; PASICK, J.; PAVADE, G.; PEREDA, A.; PEIRIS, M.; SAITO, T.; SWENSON, S.; VAN REETH, K.; WEBBY, R.; WONG, F.; ZANELLA, J.C. Review of influenza A virus in swine worldwide: a call for increased surveillance and research. Zoonoses and Public Health, v.61, p.4-17, 2014. DOI: 10.1111/zph.12049.

VINCENT, A.L.; WENJUN M.; LAGER, K.M.; JANKE, B.H.; RICHT, J.A. Swine influenza viruses: a North American perspective. Advances in Virus Research, v.72, p.127-54, 2008. DOI: 10.1016/S0065-3527(08)00403-X.

WORLD ORGANISATION FOR ANIMAL HEALTH. WAHIS interface: weekly disease information. 2016. Available at: $<$ http:// www.oie.int/wahis_2/public/wahid.php/Diseaseinformation/WI $>$. Accessed on: 18 Feb. 2016.

ZLOTOWSKI, P.; DRIEMEIER, D.; BARCELLOS, D.E.S.N. de. Patogenia das diarréias dos suínos: modelos e exemplos. Acta Scientiae Veterinariae, v.36, p.s81-s86, 2008.

Recebido em 1 de outubro de 2015 e aprovado em 1 de março de 2016 